\title{
Mobile phones use by urban refugees in South Africa: Opportunities and challenges
}

\author{
Kasky Bisimwa \\ University of Cape Town \\ kaskymiami@yahoo.fr
}

\author{
Prof. Irwin Brown \\ University of Cape Town \\ irwin.brown@uct.ac.za
}

\author{
Prof. Kevin Johnston \\ University of Cape Town \\ kevin.johnston@uct.ac.za
}

\begin{abstract}
The utilization of mobile phones is increasingly seen as a crucial means of reducing inequalities and ensuring people's inclusion in society. Yet, an understanding of the factors affecting the use of mobile phones remains inadequate. Drawing from Sen's capability approach and Bourdieu's theory of practice, the findings suggest that mobile phone use affords valuable capabilities to the users. However, the generation of these capabilities is contingent on power relations in the social field - between social structures and individual's agency. In South Africa, the capabilities of empowerment that urban refugees can generate through mobile phone use are either enhanced or hindered by interrelated factors, namely the affordances of mobile phones, socio-environmental factors, and personal factors. This paper contributes to the theory in the field of Information Systems by proposing a dynamic framework with precise constructs for theorizing and explaining the mechanisms and social practices that shape mobile phone use and the capabilities for empowerment.
\end{abstract}

\section{Introduction}

Information and communication technology (ICT) has increasingly become an important part of current development agendas, in which it has been viewed as a key component in the effort to develop the information society, alleviate socioeconomic exclusion and poverty, and enhance the empowerment of disadvantaged groups in developing countries [1]. This study aims to critically explore the factors which shape the use of mobile phones by urban refugees in South Africa and their capabilities for empowerment. In this paper, empowerment is referred to as the "expansion in people's ability to make strategic life choices in a context where this ability was previously denied to them" [2] (p. 437). Refugees have repeatedly been identified by the United Nations as belonging to a category of marginalized and vulnerable groups that need to be empowered [3].

The motivation for this study arises from the particular historical moment in which it is situated. On the one hand, while the urban refugee phenomenon has become a global concern, particularly since the declaration of the European refugee crisis which began in 2015 when a rising number of refugees, coming from the Middle East and North Africa, made their journey to Europe [3], South Africa has experienced an enormous increase in refugees since the end of the apartheid era [4]. On the other hand, the potential of mobile phones as catalysts of development is recognized worldwide [5]. Yet, little is known about the use of mobile phones by urban refugees and its impact on their lives [6]. Hence, a critical understanding of the use of mobile phones by urban refugees in South Africa and their capabilities for empowerment is crucial. As James [7] argues until now there is a dearth of research which focuses on conditions that might shape mobile phones' use. Little has been done in exploring the factors that shape the extent to which capabilities can be generated from ICT utilization [8][9]. As such, the extent to which mobile phone usage can affect urban refugees' empowerment remains under-researched.

The objectives of this study are set out as follows: (1) to empirically investigate whether the use of mobile phones by urban refugees in South Africa generates (or fails to generate) capabilities for empowerment; and (2) to critically investigate which factors or conditions enable or hinder urban refugees from generating capabilities through mobile phone use. As such, critical ethnographic methods have been used to answer the following research questions: (1) what factors shape mobile phone use by urban refugees in South Africa?; and (2) how does mobile phone use enable the capabilities for the empowerment of urban refugees in South Africa? This study is theoretically based on the integration of Sen's Capability Approach (CA) [10][11] and Bourdieu's Theory of Practice (TOP) [12][13] to explain empowerment through the use of mobile phones. In so doing, this research is based on 
and contributes to the literature on information and communications technologies for development (ICT4D) with a focus on the use of mobile phones by urban refugees in South Africa.

\section{Conceptualizing the use of mobile phone}

In the domain of ICT4D, a wide range of conceptual frameworks have been applied to research the relationship between ICTs and empowerment. It is suggested using Sen's CA as a possible theoretical lens when assessing how ICTs can contribute to improving individual well-being [14].

\subsection{Sen's Capability Approach (CA)}

Sen's CA focuses directly on the quality of life that people are actually able to achieve [15]. The CA is characterized by three interrelated concepts, but with distinct meanings: The first concept, functionings, represents the various doings or beings of an individual [11]. The second concept, Capabilities, reflects the genuine opportunities an individual enjoys or the freedom that individuals have to enjoy valuable beings and doings [17]. As such, capabilities are a person or group's freedom to achieve or promote valuable and achievable functionings [11][9]. Sen elucidates these two concepts as follows: "A functioning is an achievement, whereas a capability is the ability to achieve. Functionings are, in a sense, more directly related to living conditions, since they are different aspects of living conditions [15]. Capabilities, in contrast, are notions of freedom, in the positive sense: what real opportunities you have regarding the life you may lead" [16] (p.36). The third concept, agency, is defined as the freedom to set and pursue one's own goals and interests [10]. Agency focuses on the ability to personally choose the functionings one values.

However, as Oosterlaken [17] points out, many of the applications of CA so far have been concerned with project evaluation. He urges that investigations should also be conducted on how the expansion of human capabilities comes about. Hill [18] (p. 117) emphasizes that "until the analytical frameworks being developed as extensions of the CA address the issue of social power, the analysis of well-being will be incomplete, and decisions made to enhance human capabilities will systematically fall short”. As such, Bowman [19] calls for broader frameworks that enable an understanding of the social and cultural constraints on choice and the processes that shape the persistence of disadvantage and poverty. Consequently, this study employs a theoretical framework based on the integration of Sen's
CA and Bourdieu's TOP, to provide more insights in achieving its aim.

\subsection{Bourdieu's Theory of Practice (TOP)}

Bourdieu's TOP enables the analysis of how power persists. He points to the role of the power of symbolic systems and their domination over the construction of reality in understanding social situations [19]. In this paper, the concepts of Bourdieu's TOP are used to make sense of the relationship between "objective social structures (institutions, discourses, fields, and ideologies) and everyday practices, i.e. what people do and why they do it" [20] (p. 82). The central focus of Bourdieu's TOP is constituted by the concepts of field, capital, and habitus.

The field or fields are the "various social and institutional arenas in which people express and reproduce their dispositions, and where they compete for the distribution of different kinds of capital" [21] (p. 6). In fact, to better grasp the interactions that determine the human daily life (i.e. negotiations, discussions, conflicts, etc.), it is important to first understand the context within which these are produced. The field operates by objective social rules [22][23]. It is simultaneously a space of conflict and competition. Bourdieu and Wacquant [22] explain that agents within the field confront each other, manoeuver and struggle according to their positions in the field in the pursuit of desirable resources.

Positions that agents occupy within a particular field are regulated by power relations [24]. Such positions reflect and reinforce various status distinctions such as work activities, social group affiliation, and so on. Depending on their positions within the field, social agents are able to mobilize actual and potential capital, and also to command access to the power available in the field [22]. In other words, the position an individual occupies in the field creates self-evident rules that determine the potential limits of his social mobility within that particular social field.

Capital, also referred to as resources, is defined as "accumulated labor (in its materialized or its incorporated, embodied form) $[\ldots]$, it is a force inscribed in objective or subjective structures, but it is also the principle underlying the imminent regularities of the social world" [25] (p. 241). Each field values particular sorts of capital that agents can mobilize in order to enter and gain positions within social fields. These can comprise capital that may be economic, social, cultural or symbolic [12][13]. Economic capital refers to basic economic and material resources such as property, income, financial stocks [26]. Social capital is understood as "... [the] aggregate of the actual or 
potential resources which are linked to possession of a durable network of mutual acquaintance and recognition - or to membership in a group - which provides each of its members with the backing of the collectively-owned capital" [25] (p. 248f). Social capital represents an agent's entirety of social relations. Cultural capital is defined as people's symbolic and informational resources for action [25]. Cultural capital in the form of knowledge is "a precondition for most individual action and, as such, is a key component in people's capacity for agency" [26] (p. 238). Symbolic capital is referred to as a form of tacit power that an agent possesses and functions as an authoritative embodiment of cultural value [12]. Symbolic capital relates to honour and recognition. It is not an independent type of capital within itself, rather, it consists in the acknowledgment of capital by the entirety of the peer competitors in a specific field [12].

Individuals actively use their capital to make effective choices and translate these choices into desired actions and outcomes. As such, agents' relative positions in the field are determined by the volume and structure of their capital portfolio [22]. An agent's 'capital portfolios', allows him to "wield power, or influence in the field" [22] (p. 98). Agents' differences in capital possession and position within the field determine differing levels of power within the field. Thus, the concept of capital is important as it defines what gives some individuals power and status over others within a given field. The chance to acquire and apply those different forms of capital are predetermined and structured by an agent's habitus [26].

Habitus is defined as "... system of durable, transposable dispositions, structured structures predisposed to function as structuring structures, that is, as principles which generate and organize practices and representations that can be objectively adapted to their outcomes without presupposing a conscious aiming at ends or an express mastery of the operations necessary in order to attain them" [13](p. 53). Habitus is durable because of its "affinity" which is the inclination to create ways of doing, perceiving, working, and appreciating that sit comfortably with the habitus [12](p. 22). It is transposable because these dispositions, perceptions, and practices tend to persist even when individuals find themselves in fields, different to the original ones in which their habitus was structured [27]. It is structured in that past and present circumstances are brought together not randomly but in an ordered way [13]. It is structuring because it helps shape the present and future practices [13].

Habitus can be viewed as a set of deeply founded dispositions and beliefs rooted in the daily practices of individuals and groups which arise from personal experience and history [26]. In this way, habitus is acquired through repetition like a habit, as a result of the long-term occupation of a position within the social world and is manifested in an individual's perceptions, dispositions, feelings, thoughts, appreciation, inclinations, tastes, practices, and works. Habitus is created and reproduced unconsciously, "without any deliberation pursuit of coherence... without any conscious concentration” [28] (p. 170).

\subsubsection{The interplay of Structure and Agency in Bourdieu's view.}

Bourdieu [12] stresses that it is in the habitus that the dialectic relationship between structure and agency is manifested. As such, habitus is viewed as a structure structured by the agent's experiences of the social life, but simultaneously, habitus structures the social life in which the agent lives. This implies that involvement in a field shapes the habitus; in turn, the habitus shapes the perceptions and actions leading to a reproduction of the rules of the field [27]. By acting in conformity with the structure, the structure is confirmed and reproduced. However, an agent's actions are to be considered neither as purely impulsive nor as purely rationalized, rather it is a combination of structure and agent's consciousness [22].

In the TOP, social practice is viewed as the product of a combination of individual determination and determining structures. Bourdieu [28] (p. 101) uses the following equation to express the interplay between habitus, capital, and field: [(Habitus) (Capital) + Field] $=$ Practice.

Hence, for Bourdieu, 'practice' is understood to be the result of social structures, which are the socialized norms or tendencies, in a particular social arena 'the field' where certain rules apply and also of an individual's background, circumstances, dispositions 'habitus', and the material and symbolic assets 'capital'. Social practices are the result of structured associations and power relations in social fields.

\subsection{Re-conceptualizing ICT use in terms of Sen's CA and Bourdieu's TOP}

Drawing on Sen's CA and Bourdieu's TOP, a dynamic framework is proposed and schematized in the following figure which visualizes the inferred relationships between conversion factors, mobile phone use, capabilities, and empowerment.

This dynamic framework shows that conversion factors - social structures, the personal factors (habitus and agency), and different forms of capital are interrelated and shape the use of mobile phone, the 


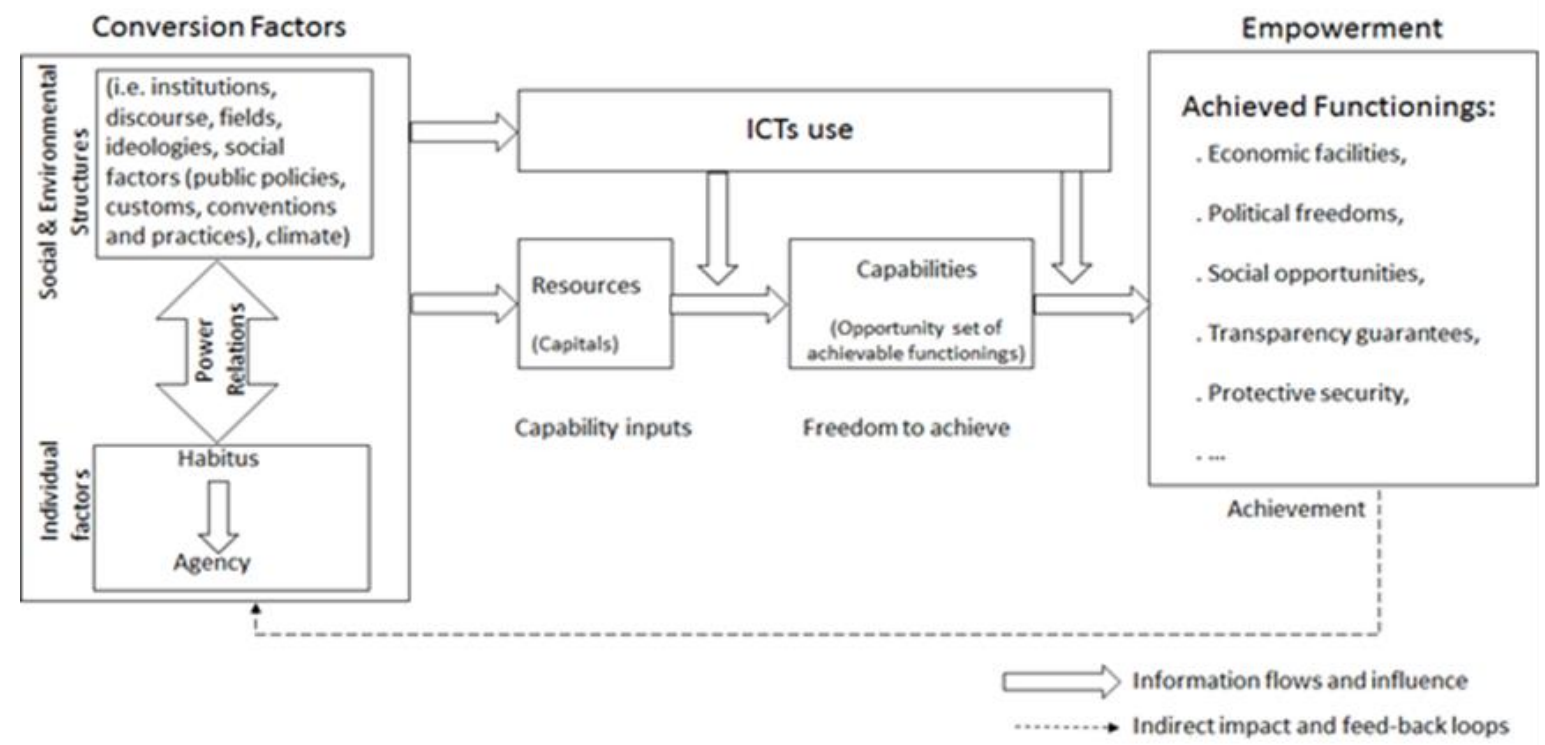

capabilities, and empowerment. The framework shows also that the use of mobile phones influences the convergence of resources (capital) into capabilities and the outcomes of empowerment.

In this framework, conversion factors are considered as consisting of a mix of internal and external structures. Internal structures or individual factors are assumed to be constituted by individuals' habitus, personal factors (such as mental and physical conditions, literacy, age, gender, metabolism, skills, etc), circumstance and life course so far. External structures refer to economic, political structures, social factors (such as social norms, public policies, customs, conventions, and practices) and environmental conditions such as geographical location, infrastructure, climate, and so on. It shows that conversion factors can affect the ability of an individual to make use of ICTs (e.g. mobile phones) in a manner that may enable the conversion of resources into capabilities for empowerment. The framework shows that these conversion factors can serve as facilitators and enablers, but also they can be hindrances or constraints for desirable actions or practices. Thus, Sen [11] (p.142) asserts that "our opportunities and prospects depend crucially on what institutions exist and how they function". As with Sen's CA, in Bourdieu's view, structures are socially defined and maintained and have enormous influence over human behavior [12]. However, Bourdieu goes further by arguing that in a particular field, social relations are not produced in a vacuum, but as an outcome of power relations [13]. For Bourdieu, social inequality is both the result and a key mechanism of the social reproduction of power and privilege [28].
ICTs use is influenced by conversion factors and can, in turn, influence the conversion of resources (capital) into capabilities for empowerment. As such, ICTs use is to be regarded as a means that can facilitate the conversion of people's capabilities to empowerment. ICTs are empowering when their use serves as a facilitator or enabler for a person - perhaps together with others in a similar situation - to achieve functionings he/she has reasons to value and functionings that can strengthen his/her effective freedom and agency. Therefore, what matters is not only what individuals are capable of being and doing with the ICTs that are available to them, but also what real opportunities (capabilities) they have to use ICTs to achieve outcomes they value. And, as this framework shows, capabilities are influenced by conversion factors which also affect ICTs use. Conversion factors affecting the use of ICTs vary according to context and have to be identified empirically. Important to note is that central to this framework is capabilities (real opportunities) and the value creation associated with the use of ICTs.

This framework highlights that individuals exercise agency but within existing social conventions, rules, resources, values, and sanctions. Individuals' actions are influenced by structural contexts, but also by their personal factors, and dispositions. As such, agency is understood as social choices influenced by habitus and operating within the limits of social structures. Agency is responsive to but not simply dependent on or determined by social structures and habitus. Rather than treating agency and structure as distinctively apart, habitus as "structuring structures" allows exploring the interrelations of individual agency and social structures [12](p.72). 
Empowerment is the outcome, the realization or effectiveness of actions. Empowerment is a dynamic process and, as such, it can be considered as both capabilities and achieved functionings [2]. The dynamic process is influenced by the feedback loops at each stage, as an individual's achieved functionings are going to re-shape his future conversation factors, capability set, and ICTs use. The process takes place in sequential periods of time and results in reproduction or transformation of social life.

\section{Research Design}

This study adopts a critical research philosophical perspective which is concerned with "social issues such as freedom, power, social control, and values with respect to the development, use, and impact of information technology" [29] (p. 17). The choice of a critical paradigm is consequent to the objectives and the context of this study. This study also adopted an ethnographic qualitative method, deemed effective for in-depth investigations of actions, behaviors, and perceptions of human actors, and for the understanding of phenomena from their point of view and the context (social and institutional) within which these perceptions were formed and actions took place [30].

I, the researcher, am also an urban refugee in South Africa. I am not only trying to scientifically understand the social world (research context) but I am experiencing it too. Being the researcher and a member of the researched community, the effort has been made "to be both insider and outsider, staying on the margins of the group socially and intellectually" [30] (p. 3). Thus, critical ethnographic methods were deemed most appropriate since they enabled me to rely on first-hand experience and observations made possible by being close, for an extended period of time, to where the action is taking place.

The data were collected through observations and in-depth interviews with 22 urban refugees in South Africa. I was interested in seeking respondents with demographic information which reflected and took account of the heterogeneity of the targeted refugee population in South Africa. As such, the range of selection criteria includes key elements such as age and gender, occupation, the length of stay in South Africa, marital status, and education background. Documents and website corroborating evidence have provided secondary data and thematic analysis was used for data analysis.

\section{Analysis of findings and discussion}

The findings show three overlapping categories of factors affecting the use of mobile phones by urban refugees in South Africa namely the affordances of mobile phones, the personal factors, and the socioenvironmental factors. It was impossible to explain one concept without mentioning the others.

\subsection{The Affordances of Mobile phones}

The affordance of mobile phones can be understood as what Orlikowski [31] refers to as the mobile phone infrastructure, which includes the services provided, the available networks, the features and functionality of mobile phone devices. The themes that emerged from the data and grouped under the categories 'affordances of mobile phones' included the ubiquity and usefulness of mobile phones and the usability of mobile phones.

Ubiquity and usefulness of mobile phones: All the respondents except three, possessed either a smartphone (fourteen respondents) or a feature mobile phone, which is a customized phone that provides internet services such as web browsing, instant messaging capabilities, and email. Fifteen respondents reported that the devices they were using were secondhand devices, bought from previous users.

It was evident for all the respondents that a mobile phone is a must-have device because of its ubiquity. Many of the respondents mentioned that they believe it is difficult to separate themselves from their devices because of personal needs. The majority stated instances in which they had trouble achieving something because either they did not have their mobile phones at hand or did not get an immediate reply from the person contacted. Respondent Tezo shared that he "always answer calls because the person who calls must have a good reason for calling...you never know; it can be a blessing like a job opportunity...also not answering calls is a sign of irresponsibility...".

The respondents' most popular activities on mobile phones included making and receiving calls, sending and receiving text messages (SMS) and photo messages, sending and receiving emails, accessing social media sites such as Facebook, WhatsApp, and imo, uploading and sharing photos and videos online. They also used their mobile phones to take photos and videos, listen to stored music, watch short videos and play games that were downloaded on the mobile phone, store contact information, and get information (news, entertainment) from the internet. Other reported activities included the use of maps or satellite navigation and online banking.

Respondents highlighted their need and desire for instant communication and interaction and argued that 
in today's world it is mobile phones that offer the best opportunity to achieve such purposes. “...people move around with their mobile phones. Whenever you need an information from someone just make a call and you will get answered immediately..." (Elena).

The majority of respondents indicated that their use of mobile phones are mostly dominated by social interactions with family and relatives who also are mostly fellow refugees living in South Africa, but also the family members and friends back in their home countries. Data showed that respondents use their mobile phones for interactions regarding social and financial issues; for business or work purposes; for education, divertissement, church, safety and advocacy purposes.

Usability of mobile phones: In relation to mobile phones, usability can be identified to consist of effectiveness, efficiency, and user satisfaction of the use of mobile phones [32]. In this research, usability is viewed as encompassing the technological features or the characteristics of the mobile phone in terms of its advantages and limitations. It emerged that certain features of mobile phones present particular advantages to the users such as the applications, the reliable connectivity, and the portability of mobile phones. However, other mobile phone features such as short sessions, and small display screen were seen as inherent constraints. The data showed that overall the opportunities and constraints inherent in mobile phones affected respondents' satisfaction with their devices.

In regard to the advantages of mobile phones, all the respondents confirmed that mobile phones are ubiquitous to them. Some respondents explained that the mobile phone is the first thing they remember when going out. Efficiency was mentioned as being what respondents like the most about mobile phones. Mobile phones offer convenience due to the faster and easy way of contact, as users are able to keep in touch with others irrespective of time and location, facilitating communication for business, work, studies, and leisure. Other reported benefits of mobile phone use relate to its features. The argument was that mobile phones have many features that allow users to achieve goals with effectiveness. Mobile phones enable respondents to manage time. They also keep their mobile phones as a lifeline to help in times of special need, as stated Binti: "... a mobile phone is so important for me to the point that even when I'm broke I must do my best to get some airtime to [pause] you never know...emergency can happen...".

Further, the data showed that depending on the technological features of a mobile phone, the user can perform activities with accuracy and completeness. These findings concur with the literature showing that mobile phones could be used for efficiency, for connectivity, and for play [32].

In regard to the disadvantages of mobile phones, respondents mentioned the costs associated with the use, such as the cost of purchasing the device, cost of airtime, internet bandwidth, repair, and loss of handset. Data show that most of the respondents have adopted different strategies to minimize the cost. These include minimizing mobile phone data usage, keeping outgoing calls as short as possible, use of SMSs, call back and flashing (generating missed calls). Respondent Shaba lamented that "In South Africa, the cost of mobile phone communication is too expensive...I use voice calls when I have to do so but I must make sure not to talk for long. Otherwise, I use SMS or callback message depending on whom I want to contact...".

Other mentioned limitations regarding the use of mobile phones included the limited processing capability such as the downloading speed and poor battery life. Also, in comparison to laptop/desktop computers, mobile phones display lower quality images resulting from reduced image resolution. And again, the performance of the mobile phone can sometimes be affected by slow and variable connectivity, as the cellular networks coverage is not equally good or universal, especially when the user is changing locations. Furthermore, poor reception and the risk of losing the device were among things respondents listed against mobile phones.

The time wasting and distraction due to the devotion to the mobile phone, and also the annoyance because of being constantly reachable were also mentioned as disadvantages of mobile phone. These findings concur with those of Hall and Pennington [33], who showed that greater connectivity provided by mobile phones comes with the possibility of dependency and anxiety.

\subsection{The Personal Factors that shape the use of Mobile phones by Urban Refugees in South Africa.}

The themes that were grouped under the category 'personal factors' included the necessity of a mobile phone and awareness of its features, the availability of or lack of financial resources, the frustration of being excluded, and the lack of confidence in the English language.

The necessity of a mobile phone and awareness of its features: For all the respondents, mobile phone use has become a necessity in their daily life routines because of the phone's values and properties which can satisfy their personal needs. Respondent's personal needs that motivated the use of a mobile phone included the needs of social interaction, needs of 
identification or recognition, needs of information and entertainment, needs related to safety or security, and job-related needs. Some examples of personal needs that led to the use of mobile phones were evidenced in respondents' comments such as: “...I must have my mobile phone with me anytime because things can happen...", “...I always need to be able to communicate with others at anytime anywhere ... that is what mobile phone does...", "....we need to be able to reach out to one another whenever we feel that desire and mobile phones make it possible ...". As with Bacishoga at al. [6], these findings reflect that respondents' increased desire for satisfying their own needs had influenced the use of mobile phones. However, while respondents' familiarity and personal experiences of satisfaction with the use of mobile phones appear to have an influence on their motivation to use a mobile phone, it has also led to a dependency on it. For example, respondent Netia comments that she always wants and enjoys having a mobile phone, for it procures her direct access to people she needs to interact with. Similarly, respondent Mika stated that he needs a mobile phone because it is enjoyable and provides to him "a feeling of freedom to do things anytime...".

Data showed that at certain instances respondents perceived a certain level of comfort, pleasure, and satisfaction through the use of mobile phones. Respondents' familiarity and personal experience with mobile phones appear to have resulted in positive attitudes towards their use. Respondents perceive and expect that mobile phones can afford them many outcomes or possibilities for action. Respondent Gatera explains: “...I'm comfortable with my mobile phone ... I'm used to it...I access the internet easily and do whatever I want ... it is just like a computer...".

Clearly, respondents' perceptions that mobile phones can enable many possibilities result from their awareness of features of their devices. Some of the respondents, however, appear to be lacking the knowledge and skills necessary to efficiently use the features of their mobile phones. For example, respondent Seleo was not aware that it is possible to access Google maps on his 'iPhone 4S' smartphone and respondent Netia was not aware that she could check her bank account balance on her Samsung Galaxy S4. These findings are supported by literature such as Newman et al. [35] and others who cited lack of skills to use and/or unawareness of potential resources among the barriers to effectively use and benefit from ICTs.

Affordability in terms of income: The data suggest that the availability of, or lack of financial means, shapes the use of mobile phones by urban refugees in South Africa.
Money is needed for purchasing a mobile phone and also for being able to use it on a regular basis. The respondents whose mobile phones were neither smartphones nor feature phones showed interest in having smartphones, but do not have enough money to purchase one. They explained that most of the time when they need to use the internet they walk to the internet cafés but occasionally they use their friends' mobile phones. They all noted that when borrowing mobile phones from friends to access the internet, the owners sometimes ask for money to cover the cost of internet data.

As with Johnston and Bacishoga [34], the findings show that affordability can inhibit meaningful use of mobile phones among low-income users. All the respondents believed that mobile phone interaction through social media is more affordable than through voice calls and SMSs. However, the former remains unreliable because not everyone possesses mobile phones with internet capability and sometimes some people switch off their cellular data so as to save costs and the battery life. The price of high-end mobile phones is beyond the affordability of most of the refugees in South Africa [6].

The frustration of being excluded: The frustrations of being excluded from many aspects of life, including from some activities in which mobile phones would be of use, were evident in respondents' narratives. Whereas in many instances the data showed respondents' positive expectations regarding the use of mobile phones, there was also evidence of negative aspects and expectations resulting from the respondents' frustration resulting from their experiences of social exclusion. Dezia complains: “...it is not everything you see on TV adverts or hear or see people doing that you can also do ... things like online booking, online banking, and more online [laughing], we could also benefit from such things with our mobile phones ... I don't waste my time because I know they won't allow refugees..."

Social exclusion has been highlighted among the important challenges experienced by urban refugees in South Africa [6]. The frustration which the experiences of social exclusion place on urban refugees in South Africa appear to have provided the basis for their autoexclusion in certain areas of activities in which they could use their mobile phones. As with respondent Dezia, many respondents showed skepticism about refugees' use of mobile phones for engaging in certain activities. Respondent Shaba claims that he does not know much about mobile money transfer and he cannot try doing it because he thinks "it must be risky for refugees... I only know that with a South African ID [Identification Document] it is possible to send or 
collect money through Shoprite and it is better than through Banks, but refugees are not allowed...".

The narratives show that due to the frustration of being excluded, many respondents believe that certain opportunities enabled by the use of mobile phones are not for refugees. The findings show that the roots of such frustration lie in the past experiences of being excluded. Such frustration can contribute - through habitus - to a re-iteration of social patterns of selfexclusion. Hence, self-exclusion tends to limit their opportunities to use mobile phones to extend their horizons. The excerpts show an example of respondents' self-exclusion from using mobile phones for activities in which they believe they are excluded. In so doing, the individuals might miss the opportunities that are at hand with the use of mobile phones.

Lack of confidence in the English language: data show that language, which is the primary means of communication, may turn into an impediment for engaging in a conversation through mobile phones or face-to-face, or in establishing relationships with others. The lack of confidence in the English language which is the main medium of communication in urban South Africa appears to impede the use of mobile phones by certain respondents to engage in a conversation with individuals other than those from the same country. Binti shared that: "...When my music album was ready I needed to promote the sell on Facebook, phone calls, SMSs ... Not knowing English well became a problem. Some people were calling. I can't hear everything they say ... we communicate by SMS or chats it ok but voice calls in English uh uh..."

Language is not only a means of communication. It also has power for individual experiences as a means for negotiating pathways within set structures. Hence, because of unfamiliar language or lack of confidence in the local languages (i.e. English or other South African national languages), many of the respondents could not benefit from the convenience that mobile phones afford. The findings show that in the case of lack of language proficiency, many respondents prefer face-to-face communication or at least written communication in the form of SMSs and chats, rather than voice calls.

\subsection{The Socio-environmental factors that shape the use of Mobile Phones by Urban Refugees in South Africa}

The themes that were grouped under the category 'socio-environmental factors' included social influences, policies, and regulations.

Social influences: It emerged that for all the respondents, owning a mobile phone is viewed as an accountability, an obligation to be available to friends and relatives. In every single respondent's narratives, there were clear evidences of direct or indirect social influences on their use of mobile phones. Those included relatives' and friends' opinions and experiences, word-of-mouth, tendencies, trends, norms, practices, public discourse, and media. These findings concur with previous studies such as Kim [5] and James [7] showing that social influences play a key role in individual behavioural intention to use a mobile phone.

Evidence of social influences on the use of mobile phones was identified through respondents' comments such as "...got invitation from a friend to join Facebook...", “...I realized that everybody is on social media...", "...adverts of free communication using WhatsApp...", “...everyone is using a mobile phone to keep in touch...". It emerged that social influence is not only the motivation for using mobile phones in a particular way or in engaging in a certain activity but also one of the reasons for the frequency and mode of communication on mobile phones.

Respondent Dina emphasized “... I wanted it so bad [talking about a smartphone] because everybody is asking me my Facebook address, or WhatsApp... today people can call or SMS you only if it is urgent. For keeping in touch like to maintain your relationships you have to join social media. Otherwise, you will be like forgotten...". Such excerpt shows that respondents consciously and unconsciously accepted the influence of peers. They perceive and use their mobile phones in certain ways in exchange for acknowledgment or recognition in a social group. As Lin et al., [36] argue, attitudes or actions influenced by peers are a form of identification and compliance process.

In addition to the influence of peers, some respondents revealed that the explicit statements or promises about the services that network service providers make increase users' awareness, which in turn motivates their use.

Policies and regulations: Many respondents are struggling to fully capitalize on the benefits that mobile phones could offer in various activities because of policies and regulations that directly or indirectly affect their use of mobile phones. As Gordon [4] argues, the legitimacy of documentation provided to refugees in South Africa remains unrecognized by most employers. The data show instances when many respondents missed opportunities they could have gained using their mobile phones. Respondent Netia explained: "One day I saw an advert on TV about a certain smartphone on promotion in one retail shop. But when I went there I was told that I have to provide a South African ID [identity document] to be able to 
buy that phone". Nastia complained that she missed an opportunity in which she could save a lot of money on a flight ticket just because she was not able to book on time using her mobile phone. This happened because the banking services enabled on her mobile phone are limited to basic activities such as checking the balance and buying airtime. Such excerpts exemplify the experience of urban refugees in South Africa. Being completely or partly excluded from certain services jeopardizes their capabilities to effectively use their mobile phones for certain services, but also hinders the achievement of related outcomes.

Further, the findings suggested that some of the respondents are aware of and interested in opportunities that they believe the use of mobile phones would facilitate, such as m-commerce and $\mathrm{m}$ banking, but they find themselves unable to capitalize on these due to certain policies and norms which exclude them.

\section{Conclusion- a critical reflection of the research findings}

This paper put together precise constructs for better theorizing and explaining the mechanisms and social practices that shape mobile phone use and the capabilities for empowerment. The framework emphasizes the importance of the individual user of mobile phones and the local structural context agency and social structures. It suggests that researchers on mobile phone use for empowerment need to look beyond social agents' immediate behaviours to take into consideration the broader context of social exclusion by focusing on conversion factors, human diversity, and capabilities. As such, this research contributes to the body of knowledge in the field of Information Systems since it discovered much that was previously unknown about factors that enable or hinder urban refugees in South Africa from generating capabilities for empowerment through mobile phone use.

The contextually rich critical ethnographic strategy used in this study contributes to Information Systems research methodology. This study is probably the first empirical ethnographic research on mobile phone use by refugees in developing countries conducted by a refugee. I embarked on this research with personal concerns and a fixed view towards the experience of mobile phone use by urban refugees in South Africa. However, throughout the fieldwork, I learned that such experiences are multiple and more complex. Based on my experience with this research, I agree with Walsham [37] that as researchers, we should see ourselves and behave as co-contributors to knowledge, with everyone else but not as experts, bringing topdown knowledge about the role and value of ICTs in development.

This research has shown that to achieve mobile phones related potentials, relevant socio-environmental factors, personal factors, and the technological context of mobile phones are critical. As such, its findings can feed into the policy-setting processes of government or organizations seeking to assist urban refugees by facilitating the formulation of their intervention strategies. In addition, by bringing to light the factors that shape mobile phone use by urban refugees, it is evident that this research has exposed the explicitly or implicitly hidden interests, important beliefs, assumptions and social practices that facilitate or constrain capabilities for empowerment.

This study has attempted to critically explore the factors which shape the use of mobile phones by urban refugees in South Africa and their capabilities for empowerment. Nevertheless, because of the limited space in this paper, the capabilities associated with mobile phone use by urban refugees in South Africa were not presented. In addition, this research has been conducted only with a specific group of the population experiencing social exclusion and inequality. Therefore, future research, using the proposed framework, could be of benefit through a rich investigation of mobile phone use and the empowerment of underprivileged communities with varying challenges.

\section{References}

[1] Avgerou, C. Discourses on ICT and Development. Information Technologies \& International Development, 2010, 6(3), pp. 1-18.

[2] Kabeer, N. Resources, agency, achievements: Reflections on the measurement of women's empowerment. Development and change, 1999 30(3), 435-464.

[3] Papademetriou, D. G., \& Fratzke, S. Beyond Care and Maintenance: Rebuilding Hope and opportunity for refugees. Washington, DC: Migration Policy Institute. 2016

[4] Gordon, S. Welcoming refugees in the rainbow nation: contemporary attitudes towards refugees in South Africa. African Geographical Review, 2016 35(1), 1-17.

[5] Kim, Y. Mobile phone for empowerment? Global nannies in Paris. Media, Culture \& Society, 2016 38(4), 525-539.

[6] Bacishoga, K. B., Hooper, V. A., \& Johnston, K. A. The Role of Mobile Phones in the Development of Social Capital. The Electronic Journal of Information Systems in Developing Countries, 2015, 72. 
[7] James, J. Patterns of Mobile Phone Use in Africa. In The Impact of Mobile Phones on Poverty and Inequality in Developing Countries Springer International Publishing; 2016. (pp. 61-87).

[8] Qureshi, S. Information technology for development in expanding capabilities. Information Technology and Development, 2011, 17(2): 91-94.

[9] Zheng, Y., \& Stahl, B. C. Evaluating emerging ICTs: A critical capability approach of technology. In The capability approach, technology and design, Springer. 2012 (pp. 57-76).

[10] Sen A. Equality of what? In The Tanner Lectures on Human Values, McMurrin S (ed.). University of Utah Press: Salt Lake City. 1980.

[11] Sen, A. Development as freedom: Oxford University Press: Oxford. 1999.

[12] Bourdieu, P. Outline of a theory of practice. Cambridge: Cambridge University Press. 1977.

[13] Bourdieu, P. The logic of practice. Cambridge: Polity Press. 1990.

[14] Gigler, B. Informational Capabilities-The Missing Link for the Impact of ICT on development. 2011. Available at SSRN.

[15] Oosterlaken, I., \& van den Hoven, J. Editorial: ICT and the capability approach. Ethics and Information Technology, 2011, 13(2), 65-67.

[16] Sen A. Gender and cooperative conflicts. Helsinki: Wider; 1987 Jul.

[17] Oosterlaken, I. The capability approach, technology and design: Taking stock and looking ahead, 2012 (pp. 3-26). Springer Netherlands.

[18] Hill, M. Development as empowerment. Feminist Economics, 2003, 9(2-3), 117-135.

[19] Bowman, D. Sen and Bourdieu: understanding inequality. Social policy working paper, 2010, (14).

[20] Donnelly, R. Critical Design and Effective Tools for ELearning in Higher Education: Theory into Practice: Theory into Practice. IGI Global. 2010.

[21] Gaventa, J. Power after Lukes: a review of the literature, Brighton: Institute of Development Studies. 2003.

[22] Bourdieu, P., \& Wacquant, L. An invitation to reflexive sociology: University of Chicago Press, 1992.

[23] Jenkins, R. Pierre Bourdieu. London: Routledge. 2002

[24] Wacquant, L. Putting habitus in its place: Rejoinder to the symposium. Body \& Society, 2014, 20(2), 118-139.
[25] Bourdieu, P. The force of law: Toward a sociology of the juridical field. Hastings LJ, 1986, 38, 805.

[26] Abel, T., \& Frohlich, K. Capitals and capabilities: linking structure and agency to reduce health inequalities. Social science \& medicine, 2012, 74(2), 236-244.

[27] Thomson, P. Field. Pierre Bourdieu: key concepts, 2008, 67-81.

[28] Bourdieu, P. Distinction: A social critique of the judgement of taste. Harvard University Press. 1984.

[29] Myers, M. D., \& Klein, H. K. A set of principles for conducting critical research in information systems. MIS quarterly, 2011, 17-36.

[30] Genzuk, M. A Synthesis of Ethnographic Research, Occasional Papers Series. Center for Multilingual, Multicultural Research. California. 2003.

[31] Orlikowski, W. J. Using technology and constituting structures: A practice lens for studying technology in organizations. Organization science, 2000, 11(4), 404-428.

[32] Hoehle, H., \& Venkatesh, V. Mobile application usability: conceptualization and instrument development. Mis Quarterly, 2015, 39(2), 435-472.

[33] Hall, J. A., \& Pennington, N. Mundane Mobile Maintenance, Entrapment, and Hyper-Coordination. In Encyclopedia of Mobile Phone Behavior, 2015, (pp. 108116. IGI Global.

[34] Johnston KA, Bacishoga KB. Impact of Mobile Phones on Integration: Case of Refugees in South Africa. The Journal of Community Informatics. 2013 May 12; 9(4).

[35] Newman, L., Browne-Yung, K., Raghavendra, P., Wood, D., \& Grace, E. Applying a critical approach to investigate barriers to digital inclusion and online social networking among young people with disabilities. Information Systems Journal. 2016.

[36] Lin, C. I., Kuo, F. Y., \& Myers, M. D. Extending ICT4D Studies: the value of critical research. MIS Quarterly, 2015, 39(3), 697-712.

[37] Walsham, G. ICT4D research: reflections on history and future agenda. Information Technology for Development, 2017, 1-24. 